\title{
EVALUATION OF BUSINESS STRATEGIC DECISIONS UNDER CHANGING ENVIRONMENT CONDITIONS
}

\author{
Virgilija Zinkevičiūtė \\ Vilnius Gediminas Technical University, Saulètekio al. 11, 10223 Vilnius, Lithuania, \\ e-mail:virgilija.zinkeviciute@gmail.com \\ Received 15 November 2006; accepted 15 January 2007
}

\begin{abstract}
A problem of strategic decisions evaluation under changing environment conditions is analyzed in this article. In the context of these conditions the use of scenarios' method, integrating scenarios formation into strategic decisions evaluation process, is perspective. The combination of multicriteria evaluation and scenarios' method allows versatile evaluation of strategic decisions in aspects of usefulness and viability regarding perspective environment situations. A universal scenarios formation technology oriented towards facilitation of scenarios creation using a graphic tool - 'Scenarios Roads 'Analysis' is offered. Methodological guidelines of strategic decisions evaluation applying multicriteria evaluation and scenarios' method combination is provided as well as their acceptability tested on experiment results.
\end{abstract}

Keywords. Business, strategic decisions, scenarios' method, multicriteria evaluation, technology, methods' combination.

\section{Introduction}

The changeability of business environment is the topicality of today and the changes of environment are considered as inevitability under conditions of which organizations must survive. Strategic decisions as a decisive factor to create competitive advantage gain significant importance under these conditions. Which way the business subject will take and where it will lead him depends on strategic decisions. The influence of strategic decisions is decisive for business subject's future; therefore the evaluation of strategic decisions is extremely important before choosing. Evaluation results must pinpoint the most suitable strategic decision for solving a strategic problem under certain conditions. The main element of strategic decisions evaluation is evaluation criteria. Wide scope of criteria increases evaluation accurateness and ensures consideration of various aspects while evaluating decisions suitability (Zavadskas, Simanauskas, Kaklauskas, 1998; Bivainis, Tamošiūnas, 2004; Ginevičius, Podvezko, 2004).

The success of strategic decisions implementation and their factorial usefulness is determined by environment forces, their dynamics and their combination formed at a certain period of time. This circumstance, evaluating suitability of strategic decisions, requires specific attention to predict changes in environment. Due to the fact, scenarios' method is very perspective. Integration of scenarios' method into strategic decisions evaluation could substantially increase validity of strategic decisions suitability. Identification of environment situation in context of strategic decisions is a difficult task as it is necessary to describe not today's situation but perspective situation of environment. Uncertainty and lack of reliable information cause perplexities at this point. This is not alien to scenarios' method therefore the application of it in strategic decisions evaluation would allow to increase expectation to make decisions which would best suit future environment situation.

Accomplished researches proved the hypothesis about the perceptiveness of multicriteria evaluation of strategic decisions and scenarios' method combination. The most relevant results of analytical research and accomplished experiment are presented in this article. Methodology of analytical research and methods of logic and synthesis were applied to find the solutions. Methods acceptability was tested by experiment. 


\section{Scenarios method application in strategic management}

According to P. J. H. Schoemaker (1997), S. M. Millett (2003), L. Fahey (2003) scenarios' method describes sequence sets of conditions and circumstances which describe the environment in which the organization will act in the future. P. Goodwin and G. Wright (2001) propose scenarios' method as an instrument for strategies' evaluation stating that the scenarios' method allows testing provided strategy in the range of probable future situations. Being unable to foresee possible scenario in the reality, consequences of every scenario are analyzed. A. Barbanente, A. Khakee (2003) emphasize scenarios' method suitability to define long term perspective in various fields given that great environment uncertainty exists. In conclusion, literary sources determine the purpose of scenarios' method as an establishment of alternative future situations.

Scenarios' method bears a descriptive character. Describing future situations expected combinations of various forces and their influence on business are presented. A distinguishing feature of scenarios' method is that it allows shaping different variants of driving forces and their possible influences. Scenarios are formed using subjective interpretation of objective analysis. While analyzing the set of possible events, expected changes are disclosed and significant information about exterior driving forces is extracted, which allows preparing and reacting adequately to their influence in advance. Herewith events expectancies are summarized and are presented in a descriptive form and the latter facilitates their perception and stimulates the process of thinking and learning in organization.

Competitive situation of an organization is determined more explicitly and its individual competitive abilities are highlighted while creating scenario (Schoemaker, 1995, 1997 and Millett, 2003). Thus the attention may be concentrated on main competitive abilities which are significant to be developed to win competition.

Scenarios and their creation are related to individuality of organization - analyzed alternatives of exterior situations are related to particular organization. Though exterior driving forces are common among similar activity organizations, every organization's attitude to driving forces and their influence is individual. The experience of specialists and organization leaders, their knowledge and personal psychological characteristics acquire specific individual reaction expression to environment situations.
There are two aims of use of created scenarios available in strategic decisions context. The first aim is to form strategic decisions (Van der Heijden, 1997; Goodwin, Wright, 2001; Barbanente, Khakee, 2003) and the second aim is strategic decisions evaluation and choice of the most suitable ones (Van der Heijden, 1997; Schoemaker, 1995, 1997; Goodwin, Wright, 2001; Barbanente, Khakee, 2003).

Scenarios' method application for strategic decisions evaluation, also for strategic decisions formation, is based on assumption that future is hard to predict and today's decisions bear influence on future situation. P. J. H. Schoemaker $(1995,1997)$, A. Barbanente and A. Khakee (2003) emphasize that evaluation based on long-term perspective anticipation has no guarantee to foresee all possible events, it is useful in making today's decisions as it considers wide and flexible future image. Such evaluation allows weighing future events, their development and helps to prepare for them.

Application of scenarios' method to evaluate strategies forming matrix of scenarios-strategies was proposed by K. van der Heijden (1997), P. J. H. Schoemaker (1995, 1997). P. Goodwin and G. Wright (2001) applied such matrix to test viability of strategic decisions. The author of the present article aims to test scenarios' method applicability and usefulness in strategic management employing a two-method combination way; to combine scenarios' method with multicriteria strategic decisions evaluation. Such complex strategic decisions evaluation in alternative scenarios frame would allow evaluating strategic decisions in aspects of usefulness and implementation under changing environment conditions.

\section{Strategic decisions evaluation model}

The need for strategic decisions evaluation appears when there is a problem of choosing strategic decisions in organization, which is initiated by the issue of finding the most suitable strategic decisions alternative. Strategic decisions in organizations are not usually structured to a formal level, i.e. strategic ideas; trends of strategic activity are generated in organizations. Considering these aspects a model for strategic decisions evaluation was created with integrated block for final strategic decisions formation prior to the stage of concrete strategic decisions multicriteria evaluation (Fig. 1). If strategic decisions in organization were formed terminatively, then the action given in final strategic decisions formation block are not carried out whereas other actions remain identical.

With reference to the created model (Fig. 1) strategic decisions evaluation starts with identification of strate- 


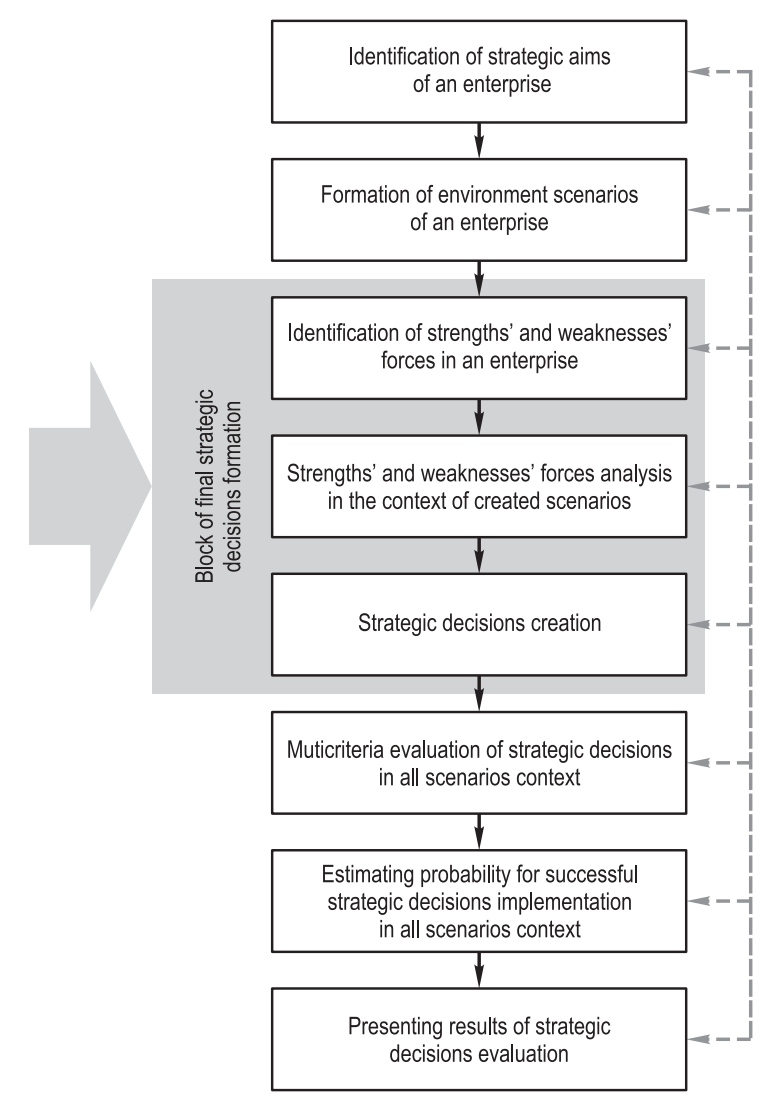

Fig. 1. Strategic decisions evaluation model

gic aims of an organization. This is necessary for purposeful and exact evaluation. Aims identify and concretize the desirable implementation result of strategic decisions evaluation which is used as a standard basis of evaluation. Identified aims are used in concretizing the set of strategic decisions primary evaluation criteria and they reduce the probability of mistakes in this step.

Scenarios of organization environment are formed in the following stages. The conditions of strategic decisions implementation in an organization are unknown, and scenarios' method allows identifying possible tendencies of exterior environment alternations and forming possible future situation scenarios on this ground.

The further stage depends on the level of terminativity of strategic decisions formation. If terminative strategic decisions do not exist, the actions from final strategic decisions formation block are conducted (Fig 1). All forces of strengths and weaknesses of an organization are named which are further analyzed separately in case of every scenario occurrence. Being uncertain which of the scenarios will emerge it is indispensable to have analysis of organization forces in the context of all scenarios. This is done in order to identify what organization forces would allow to acquire competitive advantage under occurrence of one or another scenario and what forces would block successful work of an organization. On the basis of analysis the information determining competitive advantages or reducing them is received; on the basis of this information an organization can create strategic decisions and alter its work to win competition manipulating its strengths and trying to minimize the effect of weak forces, effectively and rapidly eliminating obstacles blocking the work.

The further stage is designed for multicriteria strategic decisions evaluation in all scenarios context. Employing created evaluation criteria system in earlier stages (Bivainis, Zinkevičiūtè, 2005), strategic decisions are evaluated in case of every scenario occurrence. Hereby the combination of strategic decisions evaluation and scenarios' method allows receiving results which help to take strategic decisions considering complex information outlining suitability of every strategic decision for an organization under one or another environment condition design.

Considering the fact that there is no integrated risk criterion in strategic decisions evaluation criteria system (Bivainis, Zinkevičiūtè, 2005), identification of probabilities of successful strategic decisions implementation in context of all scenarios is carried out. This information supplements evaluation results with relevant arguments while choosing decisions as various toleration of risk is possible, the latter is individual for every organization.

Strategic decisions evaluation is finished with presentation of evaluation results. A matrix was chosen as a form to present evaluation results; strategic decisions evaluation results together with identified successful implementation probabilities in case of every decision and every scenario are presented in the matrix.

The most complex stages of strategic decisions evaluation model implementation, i.e. scenarios formation and multicriteria strategic decision evaluation are detailed in further chapters of the article. Chapter 6 presents the application results of created strategic decisions evaluation model.

\section{Formation of environment scenarios of an organization}

Scenarios formation processes described in professional literary sources and applied practically by P. R. Walsh (2005), J. Bergman, A. Jantunen, J. M. Saksa (2004), L. Fahey (2003), P. Schwab, F. Cerutti, U. H. von Reibnitz (2003), J. Ratcliffe (2000, 2001), F. Graetz (2002), P. J. H. Schoemaker $(1995,1997)$ in many cases are oriented towards specific problems and purpose of a particular scenario. Thus various specifications of sce- 
narios formation stages exist depending on the aim of scenarios application. Regarding provided scenarios formation recommendations and having analyzed scenarios creation processes, scenarios formation technology to facilitate creation process is presented.

Scenarios formation is recommended to be organized using a modification of team work, i.e. team members (experts) working together and taking decisions in every stage trying to reach consensus. Building an expert team in an organization it is important to involve experts from as wider scope as possible, the experience of which would allow increasing the quality of taken decisions. Importantly the part of expert team would be composed of organization leaders' representatives who will be responsible for implementation of taken strategic decisions in subsequent stages, likewise other essential expert selection criteria, i.e. expert competence, team work skills, awareness and perception of organization aims should be considered.

The experts start scenarios formation determining the scenarios creation task, formulating scenarios creation aim, defining direction and limits of scenarios analysis and foreseeing the perspective period. At this stage it is useful to view back overlooking business environment at the same retrospective period as the perspective period set. Retrospection helps to believe in environment changeability and also helps to set primary guidelines for scenarios creation.

The following scenarios creation stage is related to identification of driving forces and the analysis of their influence on the aims of the organization. PEST(EL) analysis forces may be used if the exterior environment of an organization is being analyzed. Great attention should be paid to determine special driving forces which may influence an organization decisively and may change its strategic direction.

After driving forces have been identified, their possible combinations are analyzed and primary scenarios are created, the amount of which according to P. R. Walsh (2005), P. Schwab, F. Cerutti, U. H. von Reibnitz (2003), J. Ratcliffe (2000, 2002), P. J. H. Schoemaker $(1995,1997)$, should not outnumber from seven to nine. At this exact stage specific space is left for experts' opinions and intuition manifestation. This stage also requires reflection on big amounts of information and systematizing it at the same time looking for possible driving forces compositions and testing them according to the principles of logic. Fig. 2 provides a graphic tool called "Scenarios Roads' Analysis", it is based on principles of morphological analysis by M. Godet (2000) and is used to facilitate the work of experts who create scenarios. The provided scheme (Fig. 2) represents the components of PEST exterior environment analysis. Identified driving forces in the company are depicted inscribing them in the empty squares indicating their influence on reaching aims of an organization; the top of the scheme shows special driving forces. Special driving forces may be singled out from any group of driving forces because they are distinguished for their special influence on organization aims. They bear presumptive character and in case they are realized they would condition the strategic decisions evaluation and choice.

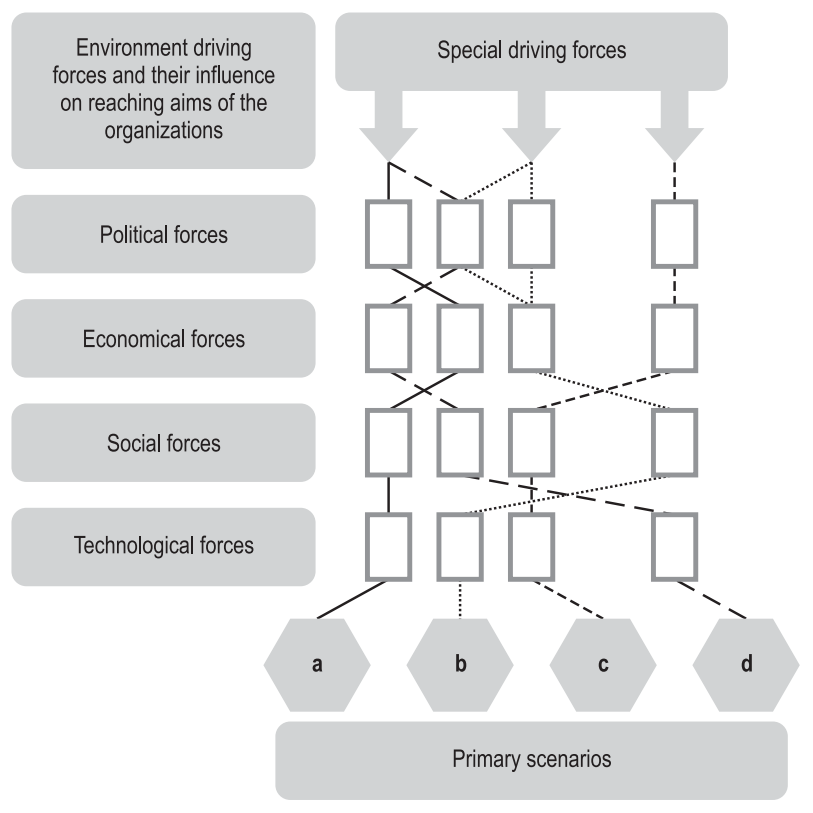

Fig. 2. Scenarios Roads' Analysis (modified by the author, according to M. Godet (2000))

All parameters of the "Scenarios Roads' Analysis" can be controlled and alternated. Both analyzed driving forces and special driving forces are individual and chosen in every organization considering the aims and situation. The main advantage of this graphic tool is that experts creating scenarios can concentrate their attention on scenarios creation process searching for possible driving forces combinations.

Created primary scenarios are assessed according to criteria of logic (Walsh, 2005; Fahey, 2003; Ratcliffe, 2000, 2002), plausibility (Walsh, 2005; Schwab, Cerutti, von Reibnitz, 2003; Schoemaker, 1995, 1997) and diversity (Ratcliffe, 2000, 2002; Schoemaker, 1995, 1997). Assessed scenarios are analyzed and refined in further formation of final scenarios. The number of final scenarios is from two to four; this number is recommended by P. R. Walsh (2005), P. Schwab, F. Cerutti, 
U. H. von Reibnitz (2003), J. Ratcliffe (2000, 2002), F. Graetz (2002), P. J. H. Schoemaker (1995, 1997), K. van der Heijden (1997).

Scientific theory and practice distinguish characteristics of final scenarios; they must be short, memorable and not overloaded with redundant information. Scenarios are given suitable, sharp and exceptional names. It is necessary if you decide to use scenarios for organizational learning purposes.

\section{Muticriteria evaluation of strategic decisions}

Strategic decisions evaluation is very complicated because of indefiniteness and different content decisions characteristics, the part of which is of qualitative character. This accounts for active discussions in special sources about evaluation method's suitability where different evaluation criteria are suggested together with different evaluation algorithms.

The choice of evaluation criteria is on the one hand responsible, on the other hand an intricate task. Applied criteria determine reasoning of evaluation. Employing a wide scope of evaluation criteria guarantees resourceful and detailed evaluation of strategic decisions. A complex three-level strategic decisions evaluation system is used in the present research; it was prepared (Bivainis, Zinkevičiūtè, 2005) considering versatile requirements raised for evaluation criteria. The first criteria level is composed of primary evaluation criteria set, which in order to thoroughly evaluate strategic decisions suitability in an organization is made of both qualitative and quantitative evaluation criteria. Primary strategic decisions evaluation criteria regarding their intercomparability and content identity are combined into five partly autonomic criteria groups (Table 1). The present groups coincide with second level criteria, which are called as partly integrated, and the latter are joined into complex integrated criteria at third level.

Such composition of evaluation criteria system allows subdividing the multicriteria evaluation process into simpler operations. Firstly, strategic decisions are evaluated according to the first level criteria. The second level, i.e. partly integrated criteria values are counted based on first level evaluation results. The third level, i.e. complex integrated criterion value is counted using criteria values from the second level.

Complex evaluation of strategic decisions according to provided criteria system (Bivainis, Zinkevičiūtè, 2005) starts from identifying the weights of primary evaluation criteria separately in each primary criteria group as well as identifying the weights of partly integrated criteria. Criteria are easily inter-compared within the group; the number of analyzed criteria is not large and this facilitates the determination of weights.

Table 1. Criteria groups of strategic decisions evaluation

\begin{tabular}{|c|c|c|}
\hline First level - primary criteria & $\begin{array}{c}\text { Second } \\
\text { level - partly } \\
\text { integrated } \\
\text { criteria }\end{array}$ & \\
\hline $\begin{array}{l}\text { 1.1. Compatibility with political } \\
\text { forces }\end{array}$ & \multirow{5}{*}{$\begin{array}{l}\text { 1. Partly } \\
\text { integrated } \\
\text { compatibility } \\
\text { with exterior } \\
\text { forces } \\
\text { criterion }\end{array}$} & \\
\hline $\begin{array}{l}\text { 1.2. Compatibility with } \\
\text { economical forces }\end{array}$ & & \\
\hline $\begin{array}{l}\text { 1.3. Compatibility with social } \\
\text { forces }\end{array}$ & & \\
\hline $\begin{array}{l}\text { 1.4.Compatibility with } \\
\text { technological forces }\end{array}$ & & \\
\hline $\begin{array}{l}\text { 1.5.Compatibility with ecological } \\
\text { forces }\end{array}$ & & \\
\hline 2.1. Compatibility with mission & \multirow{5}{*}{$\begin{array}{l}\text { 2. Partly } \\
\text { integrated } \\
\text { compatibility } \\
\text { with interior } \\
\text { forces } \\
\text { criterion }\end{array}$} & \\
\hline 2.2. Compatibility with aims & & \\
\hline $\begin{array}{l}\text { 2.3. Compatibility with human } \\
\text { resources }\end{array}$ & & \\
\hline $\begin{array}{l}\text { 2.4. Compatibility with financial } \\
\text { resources }\end{array}$ & & \\
\hline $\begin{array}{l}\text { 2.5. Compatibility with material- } \\
\text { technological resources }\end{array}$ & & \\
\hline 3.1. Net present value & \multirow{5}{*}{$\begin{array}{l}\text { 3. Partly } \\
\text { integrated } \\
\text { economical- } \\
\text { financial } \\
\text { criterion }\end{array}$} & \\
\hline 3.2. Internal rate of return & & \\
\hline 3.3. Rate of return & & \\
\hline 3.4. Return on common equity & & \\
\hline 3.5. Payback period & & \\
\hline 4.1. Strategic decision flexibility & \multirow{5}{*}{$\begin{array}{l}\text { 4. Partly } \\
\text { integrated } \\
\text { competition } \\
\text { criterion }\end{array}$} & \\
\hline 4.2. Strategic decision uniqueness & & \\
\hline $\begin{array}{l}\text { 4.3. Strategic decision advantage } \\
\text { over competitors }\end{array}$ & & \\
\hline 4.4. Added value & & \\
\hline 4.5. Value for consumer & & \\
\hline $\begin{array}{l}\text { 5.1. Compatibility of values with } \\
\text { partners }\end{array}$ & \multirow{4}{*}{$\begin{array}{l}\text { 5. Partly } \\
\text { integrated } \\
\text { corporate } \\
\text { culture } \\
\text { criterion }\end{array}$} & \\
\hline $\begin{array}{l}\text { 5.2. Compatibility of values with } \\
\text { employees }\end{array}$ & & \\
\hline $\begin{array}{l}\text { 5.3. Strategic decision congruence } \\
\text { with corporate culture }\end{array}$ & & \\
\hline $\begin{array}{l}\text { 5.4. Extent of motivation for } \\
\text { decision implementation }\end{array}$ & & \\
\hline
\end{tabular}


Having identified the weights of primary evaluation criteria, strategic decisions are evaluated according to every primary criterion. Strategic decisions according to qualitative criteria are assessed in the interval form $[0,1]$, the latter assessment was applied in the works of P. Goodwin, G. Wright (2001) and others. Applying this interval the highest evaluation is attributed to one (e.g. "high compatibility" - 1); zero is attributed to the lowest evaluation (e.g. "incompatibility" - 0 ). In marginal interval the value of evaluation is set to every strategic decision. The latter rarely matches the value of 0 and 1 . In such cases, transitional values are used as for example "intermediate compatibility" -0.5 , "satisfactory compatibility" - 0.4 , "slight compatibility" -0.2 , etc. arranging them in the interval $[0,1]$ in logical sequence.

According to primary quantitative criteria strategic decisions are assessed by rating the values of determining indexes of every criteria content. It can be of absolute and relative magnitude. Trying to reach the rated index as criteria compatibility (note: it can be realized in different measure units), they are normalized, i.e. translated into dimensionless, right for comparison shape. To normalize the rate in the interval $[0,1]$ as a tool for further rating the following formulae are applied: maximizing criteria values

$N_{i}=1-\frac{N_{i}^{*}-N_{i t}}{N_{i}^{*}-N_{i}^{0}}$

minimizing criteria values

$N_{i}=\frac{N_{i}^{*}-N_{i t}}{N_{i}^{*}-N_{i}^{0}}$,

therein $N_{i}$ - normalized rating value in interval $[0,1]$; $N_{i}^{*}$ - possible highest evaluation value; $N_{i t}$ - factual evaluation value; $N_{i}^{0}$ - lowest acceptable evaluation value.

Value of complex integrated criterion is calculated according to such formula:

$R^{\prime}=\omega_{1}^{*} \sum_{i=1}^{l} R_{1 i} \cdot \omega_{1 i}+\omega_{2}^{*} \sum_{i=1}^{l} R_{2 i} \cdot \omega_{2 i}+\omega_{3}^{*} \sum_{i=1}^{l} R_{3 i} \cdot \omega_{3 i}+$

$\omega_{4}^{*} \sum_{i=1}^{l} R_{4 i} \cdot \omega_{4 i}+\omega_{5}^{*} \sum_{i=1}^{l} R_{5 i} \cdot \omega_{5 i}$,

therein $R^{\prime}$ - the value of complex integrated criterion; $\omega_{i}{ }^{*}$ - weight of a partial integrated criterion; $j$ - primary criteria group index; $R_{j i}$ - normalized value of a primary criterion; $\omega_{j i}-$ a primary criterion weight; $i$ - a primary criterion index; $l$ - number of criteria in the group.

\section{Application of strategic decisions evaluation model in organization " $\mathrm{X}$ "}

The experiment was carried out in an organization " $\mathrm{X}$ " engaged in publishing weekly newspapers. A four year period was analyzed. Strategic decisions suitability was analyzed as the possibility to survive the competition retaining "M" weekly newspaper at the same time.

Expert group designated the main driving forces of perspective environment which may influence the achievement of set goals. Political, economic, social, technological and branch driving forces and their influence were discussed. Having estimated driving forces, special forces for "M" weekly newspaper were distinguished, the influence of which was extremely strong; in the given case: passing favourable laws for intermediate business, monopoly concern establishment, loss of cheap printing services. Employing "Scenarios Roads' Analysis" (Fig. 3) primary scenarios were created, final scenarios were assessed and formed and the latter were designated as: "Monopoly", "Growth of Cost" and "Free Market" (Table 2).

Table 2. Exterior environment scenarios of weekly newspaper "M"

\section{Scenario essence}

Monopoly concern entrenches in the market, cases of dumping become more often. Competitive positions of an organization weaken and the circle of loyal readers contracts because the consumers choose concern funded cheap or free of charge newspapers. Declining number of readers and monopoly of circulation agencies which dictates higher prices forces an organization to increase the price of a weekly newspaper. Declining circulation and popularity of a weekly aggravates attracting promotion and blocks expansion of a weekly.

The organization looses a possibility to print a weekly at a reasonable price; the net of alternative publishing houses belongs to a concern which raises the prices using the power of a supplier. The higher price of paper in the world market also influences the increase in printing service price. An organization is forced to raise the sale-price of a weekly which contracts the number of consumers and makes an organization direct its power to investments in online press development. Such step is also stimulated by the increasing volume of advertising agencies, disfavour of subscription for a consumer and monopoly of circulation agencies.

Favourable laws for intermediate business are passed, monopoly establishment is limited, and dumping application is restricted by laws. Ameliorative economical situation conditions increase number of consumers. Boosting costs of qualified work force increase expenses for attracting qualified personnel whereas increasing paper costs in the world market determine higher printing costs. Growing need for information causes the expansion of a weekly newspaper, involves additional topics and attracts sponsoring promotion. 


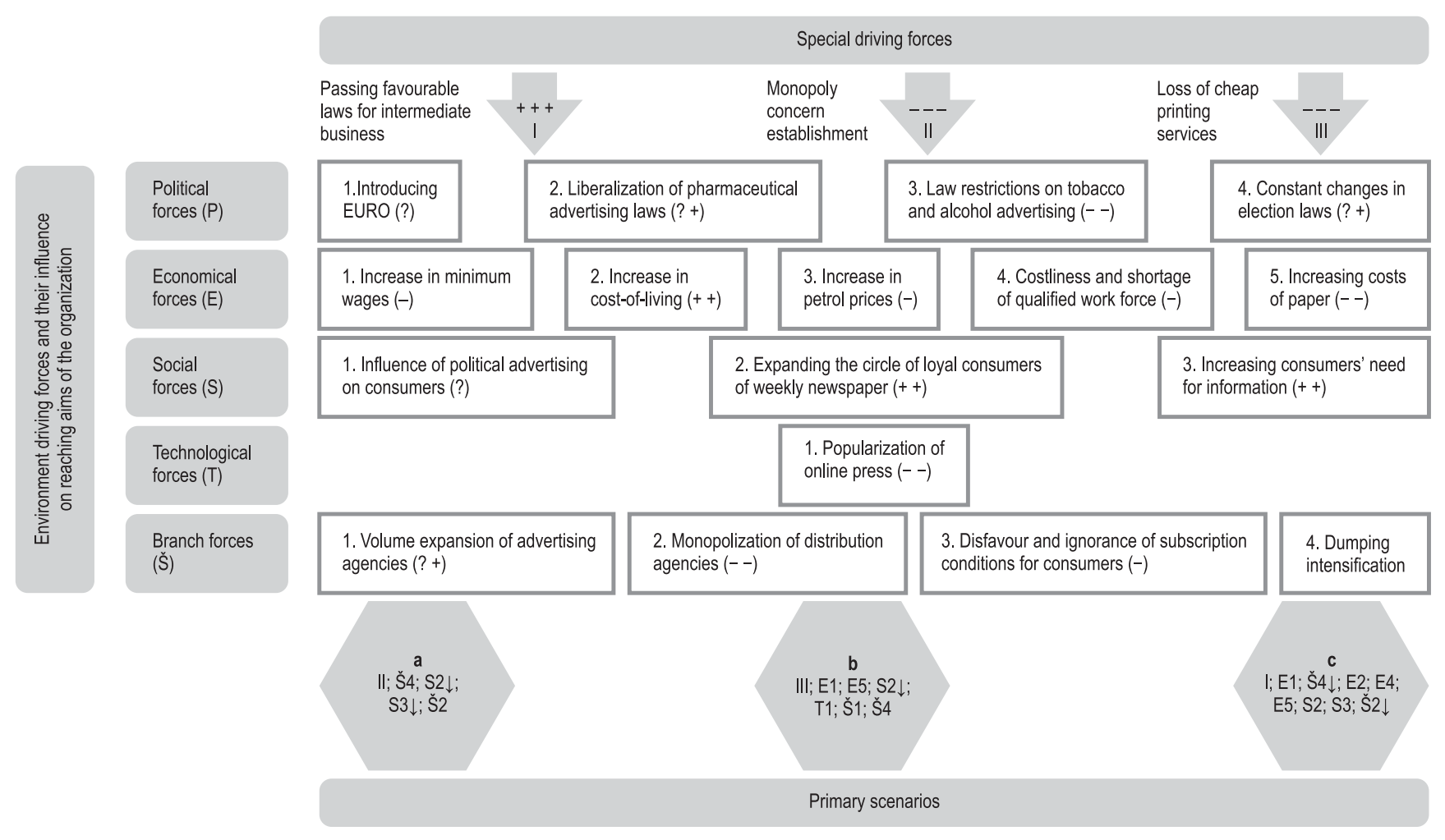

Fig. 3. "Scenarios Roads"Analysis" made in company "X"

Using created scenarios the analysis of strengths and weaknesses of organization was carried out for every case of concrete scenario. Being uncertain which scenario will materialize, three strategic decisions which were evaluated in the context of all scenarios were formulated. The following strategic decisions were formulated: first - the organization invests into publication representation and expands promotion; second - the organization expands the onlines activity of the newspaper; third - the organization expands the quality of the newspaper in a broad sense.

Using consensus method the expert group estimated the weights of both primary and partly integrated criteria. Usefulness of strategic decisions was assessed according to strategic decisions evaluation technology presented in the paragraph 5. Before strategic decisions evaluation the experts analyzed prepared environment scenarios and strategic decisions according to primary criteria (Table 1) and estimated regarding characteristics of environment scenarios.

The values of integrated complex criteria were calculated according to formula (4). During the last stage of expert evaluation method, probabilities of successful implementation of every strategic decision which depends on every environment scenario were identified. The leaders of the organization were presented the evaluations together with the results of integrated complex evaluation in the shape of the matrix (Table 3).
Table 3. Strategic decisions evaluation results

\begin{tabular}{|l|c|c|c|c|c|c|}
\hline \multirow{2}{*}{$\begin{array}{l}\text { Strategic } \\
\text { decisions }\end{array}$} & $R^{\prime}$ & $\tau$ & $R^{\prime}$ & $\tau$ & $R^{\prime}$ & $\tau$ \\
\cline { 2 - 7 } & "Monopoly" & $\begin{array}{l}\text { "Growth } \\
\text { of Cost" }\end{array}$ & \multicolumn{2}{|c|}{$\begin{array}{c}\text { "Free } \\
\text { Market" }\end{array}$} \\
\hline $\begin{array}{l}\text { First strategic } \\
\text { decision }\end{array}$ & 0,84 & 0,35 & 0,84 & 0,87 & 0,77 & 0,90 \\
\hline $\begin{array}{l}\text { Second strategic } \\
\text { decision }\end{array}$ & 0,47 & 0,35 & 0,70 & 0,56 & 0,48 & 0,75 \\
\hline $\begin{array}{l}\text { Third strategic } \\
\text { decision }\end{array}$ & 0,32 & 0,42 & 0,12 & 0,33 & 0,58 & 0,82 \\
\hline
\end{tabular}

$R^{\prime}$ - integrated complex criteria value;

$\tau$ - successful implementation probability.

The presentation of strategic decisions evaluation results in the form of matrix gives freedom of strategic decisions choice to leaders. Evaluation results demonstrate the values of complex evaluation under one or another environment condition design, successful implementation probability presenting viability of every strategic decision under certain conditions. Strategic decisions evaluation results, without limiting opinion 
of leaders with one strategic decision presented, are useful in the sense that assumptions of strategic flexibility of an organization under changing business environment conditions are created.

\section{Conclusions}

Theoreticians and practicians unanimously admit the specific role of strategic decisions in successful organization activity. Unfortunately, strategic decisions evaluation under changing environment conditions methodological provision is the weak link in broader implementation of business strategic management.

The experiment proved that to evaluate business strategic decisions under changing environment conditions and reason their choice, a created strategic decision evaluation model can be successfully applied which integrates scenarios application for terminative formulation of strategic decisions and strategic decision evaluation. Advantages characteristic of a suggested strategic decision evaluation model:

- the decisions are being evaluated while using a broad criteria system which leaves an opportunity to fully judge the suitability of certain decisions for the business subject;

- detailed evaluation results support strategic decisions making based on business subject risk level, exterior environment situation and multicriteria evaluation results;

- evaluation becomes comprehensive, clear and visual to all business subject participants.

Scenarios formation technology is purified and a graphic tool "Scenarios Roads' Analysis" was suggested to facilitate scenarios formation. With the help of this tool, scenarios creation group can concentrate their attention on analysis of forces composition, they do not need to remember information from earlier stages which is presented in the graphic form of "Scenarios Roads' Analysis". The use of graphic view stimulates creative thinking, initiates innovation of thinking and improves quality of created scenarios.

\section{References}

BARBANENTE, A.; KHAKEE, A. (2003) Influencing ideas and inspirations. Scenarios as an instrument in evaluation. Foresight, 5(5), p. 3-15.

BERGMAN, J.; JANTUNEN, A.; SAKSA, J. M. (2004) Managing knowledge creation and sharing - scenarios and dynamic capabilities in inter-industrial knowledge networks. Journal of Knowledge Management, 8(6), p. 63-76.
BIVAINIS, J.; TAMOŠIŪNAS, A. (2004) Strategic solutions for corporate restructuring. International Journal of Strategic Property Management, 8(1), p. 45-55.

BIVAINIS, J.; ZINKEVIČIŪTĖ, V. (2005) Complex evaluation of business strategic decisions. Business: Theory and Practice (Verslas: teorija ir praktika), 6(1), p. 3-11 (in Lithuanian).

FAHEY, L. (2003) How corporations learn from scenarios. Strategy \& Leadership, 31(2), p. 5-15.

GINEVIČIUS, R.; PODVEZKO, V. (2004) Complex evaluation of the use of information technologies in the countries of Eastern and Central Europe. Journal of Business Economics and Management, 5(4), p. 183-192.

GODET, M. (2000) Forefront: how to be rigorous with scenario planning. Foresight, 2(1), p. 5-9.

GOODWIN, P.; WRIGHT, G. (2001) Enhancing strategy evaluation in scenario planning. Journal of Management Studies, 38(1), p. 1-16.

GRAETZ, F. (2002) Strategic thinking versus strategic planning: towards understanding the complementarities. Management Decision, 40(5), p. 456-462.

MILLETT, S. M. (2003) The future of scenarios: challenges and opportunities. Strategy \& Leadership, 31(2), p. 16-24.

RATCLIFFE, J. (2000) Scenario building: a suitable method for strategic property planning? Property Management, 18(2), p. 127-144.

RATCLIFFE, J. (2002) Scenario planning: strategic interviews and conversations. Foresight, 4(1), p. 19-30.

SCHOEMAKER, P. J. H. (1995) Scenario planning: a tool for strategic thinking. Sloan Management Review, 36(2), p. 25-40.

SCHOEMAKER, P. J. H. (1997) Disciplined imagination from scenarios to strategic options. International Studies of Management \& Organization, 27(2), p. 43-70.

SCHWAB, P.; CERUTTI, F.; Von REIBNITZ, U. H. (2003) Foresight - using scenarios to shape the future of agricultural research. Foresight, 5(1), p. 55-61.

WALSH, P. R. (2005) Dealing with the uncertainties of environmental change by adding scenario planning to the strategy reformulation equation. Management Decision, 43(1), p. 113-122.

ZAVADSKAS, E. K.; SIMANAUSKAS, L.; KAKLAUSKAS, A. (1998) Decision support systems in construction (Sprendimų paramos sistemos statyboje). Vilnius: Technika. 235 p. (in Lithuanian).

Van der HEIJDEN, K. (1997) Scenarios, strategies and the strategy process. In Nijenrode Research Papers Series Center for Organizational Learning and Change, p. 1-33. 